\title{
Avaliação da sustentabilidade agroambiental de unidades produtivas agroflorestais em várzeas flúvio marinhas de Cametá - Pará1.
}

\author{
Raimundo Nonato da Silveira RIBEIRO ${ }^{2}$, Manoel Malheiros TOURINHO $^{3}$, Antônio Cordeiro de SANTANA ${ }^{4}$
}

\begin{abstract}
RESUMO
O objetivo do trabalho é avaliar o potencial de sustentabilidade agroambiental de unidades produtivas agroflorestais ribeirinhas. A metodologia empregou técnicas de inventário florestal, coleta e análise laboratorial de solo, questionários, observações de campo e orçamentos unitários. As variáveis-indicadores são relativas ao clima, ao solo, a estrutura fitossociológica, ao potencial produtivo da agrofloresta e a geração de renda. Os resultados revelaram que o clima e o solo não são fatores limitantes. Cerca de 27 \% da composição florística são espécies comerciais e somam mais de $92 \%$ da população total com baixo potencial para a extração de madeiras e uma diversidade de produtos não-madeireiros. A renda bruta estimada atingiu valores de $\mathrm{R} \$ 2.000,00 / \mathrm{ha} / \mathrm{ano}$. O potencial de sustentabilidade agroambiental das unidades produtivas é mediano, obtido pela avaliação das variáveis-indicadores por meio de um sistema de pontuação e inserção em um nível de sustentabilidade previamente proposto.
\end{abstract}

PALAVRAS-CHAVE

Agrossilvicultura, sustentabilidade, várzea flúvio-marinha, Amazonia.

\section{Agro-environmental sustainability evaluation of productive agroforestry units in tidal river floodplains Cametá - Pará.}

\begin{abstract}
The purpose of this paper is to evaluate the agro-environmental sustainability potential of productive agroforestry units in tidal river floodplains. The methodology employed forest inventory techniques, soil collection and laboratory analysis, questionnaires, field observations and budget sheets. The indicator variables are relative to climate, soils, sociological plant structure, agroforestry's productive potential and the generation of income. Results revealed that climate and soil are not limiting factors. Approximately 27\% of the floristic composition is commercial species, making up over $92 \%$ of the total tree population having low timber extraction potential and a diversity of non-timber products. Estimated gross income reached sums of $R \$ 2,000.00 /$ ha/year. The agro-environmental sustainability potential of the productive units is median and was measured by evaluating the indicator variables on a point system and placed within a previously established level of sustainability.
\end{abstract}

\section{KEY WORDS}

Agroforestry, sustainability, tidal river floodplains, Amazonia.

\footnotetext{
${ }^{1} \mathrm{O}$ artigo baseia-se em parte da dissertação de mestrado do primeiro autor, orientado pelo segundo e terceiro autores.

${ }^{1}$ Article based in part on the Master's thesis of the first author, whose advisor and co-advisor were second and third authors, respectively.

${ }^{2}$ Eng $^{\mathrm{O}}$ Agr $^{\mathrm{O}}$ M. Sc. em Ciências Florestais, extensionista da EMATER-PARÁ, Marituba-Pará- rionata@interconect.com.br

${ }^{2}$ Agronomist, M.S. in Forestry Science, Extension Technician of EMATER-Pará, Marituba, Pará, Brazil - rionato@interconect.com.br

${ }^{3}$ Eng $^{\mathrm{o}}$ Agr $^{\circ}$, Ph. D. Professor Titular e Reitor da UFRA - Belém-Pará - gab@ufra.br

${ }^{3}$ Agronomist, Ph.D., Full Professor and President of UFRA [Federal Rural University of Amazonia], Belém, Pará, Brazil - gab@ufra.br

${ }^{4}$ Eng $^{\mathrm{O}}$ Agr $^{\mathrm{O}}$ D. Sc. em Economia Rural e Professor da UFRA - Belém-Pará - santana@nautilus. com. br

${ }^{4}$ Agronomist, D.Sc. in Rural Economy and Professor, UFRA [Federal Rural University of Amazonia], Belém, Pará, Brazil - santana@nautilus.com.br
} 


\section{ACTA \\ AMAZONICA}

AVALIAÇÃO DA SUSTENTABILIDADE AGROAMBIENTAL DE UNIDADES PRODUTIVAS

AGROFLORESTAIS EM VÁRZEAS FLÚVIO-MARINHA DE CAMETÁ - PARÁ

\section{INTRODUÇÃO}

As várzeas amazônicas têm assegurado a sobrevivência de grupos humanos, desde os primórdios de sua ocupação, que remonta a milhares de ano. Ainda hoje, os cursos d'água e suas margens continuam sendo estratégicos no surgimento de vilas e povoados na Amazônia.

O processo de exploração das várzeas foi intensificado do século XVI com a chegada dos europeus até os dias atuais. Nessa escalada de exploração das florestas próximas às margens dos rios, Barros \& Uhl (1996) relatam que do século XVI até meados do século XX, o extrativismo esteve mais concentrado em produtos não-madeireiros, em que se destacaram a Bertbolletia excelsa (castanha-do-pará), a Hevea brasiliensis (seringueira), raízes aromáticas e sementes oleaginosas, que eram exportadas para a Europa, originários em sua grande maioria do estuário e do baixo Amazonas. A partir dos anos setenta, a exploração de produtos florestais madeireiros ganhou impulso de tal magnitude que a participação da Amazônia no mercado nacional de madeira em tora, segundo Veríssimo et al. (1999) passou de 4,5 milhões de toras, que representavam $14 \%$ da produção nacional em 1976, para 28 milhões de toras em 1988, representando $80 \%$ da produção nacional. Tal produção, em sua maioria era proveniente da terra firme. Na várzea, o processo também se intensificou, com o abate de espécies de baixo valor econômico, destinadas à população de baixa renda, que se estabelecia nas periferias dos centros urbanos.

Apesar da exploração predatória das várzeas, quer pela extração madeireira e não-madeireira, como a extração de palmitos, quer pela sua substituição para práticas agrícolas, após cerca de 400 anos, ainda é significativo o percentual existente de florestas de várzeas.

Assim, este trabalho, objetivou avaliar o potencial de sustentabilidade agroambiental das unidades de produções agroflorestais - UPA, localizadas no município de Cametá, que têm nos sistemas agroflorestais - SAF de várzea, o meio de sobrevivência e de reprodução familiar. O conceito de sustentabilidade referido neste trabalho, compreende a capacidade do ambiente agroflorestal de fornecer e repor, de forma continuada e sistemática, sem degradação ambiental, os produtos madeireiros e não-madeireiros, capazes de garantir às famílias ribeirinhas a satisfação de suas necessidades e permanência na área. Assim, tem-se como referencial teórico a concepção do desenvolvimento sustentável, difundido a partir do Relatório de Brundtland, publicado em 1987 (Fenzl, 1997).

\section{MATERIAL E MÉTODOS}

\section{Localização da área de estudo}

As UPA objeto do estudo, em número de seis, portanto tratase de estudos de casos, estão localizadas no distrito de Juaba, município de Cametá, Estado do Pará. O distrito de Juaba possui uma população de 12.457 habitantes, dos quais 10.992 residem na área rural $(88,24 \%)$, em comunidades de terra firme e comunidades de várzeas (IBGE, 1999). A comunidade do Juba, precisamente onde estão localizadas as UPA, é constituída pelas famílias ribeirinhas moradoras do rio Juba, riozinho do Juba e rio Jubinha, totalizando 135 UPA e 168 residências, tal diferença se deve ao fato de algumas UPA possuirem mais de uma residencia que abrigam famílias dos filhos (Ribeiro, 2002).

\section{Técnicas de coleta de dados}

\section{Instrumentos e técnicas utilizadas}

Para a determinação da estrutura florestal e seu potencial madeireiro e não-madeireiro para a geração de renda e/ou consumo familiar na unidade de produção, utilizou-se a técnica do inventário florestal, em parcelas de 0,25 ha, divididos em 25 sub-parcelas.

Para a determinação da fertilidade do solo das UPA, utilizou-se a técnica da coleta de amostra composta, constituída de 25 amostras simples obtidas em cada subparcela, que foram analisadas pelo laboratório da Embrapa Amazônia Oriental, pelos métodos descritos por Guimarães et al. (1970) e pelo Serviço Nacional de Levantamento e Conservação de Solo da Embrapa (EMBRAPA, 1997).

O potencial produtivo da agrofloresta foi determinado com base no inventário florestal, nas observações de campo, índices teóricos e entrevistas com os produtores.

\section{Seleção das unidades \\ de produções agroflorestais}

A seleção das UPA seguiu a adoção dos seguintes critérios não-formais: i) UPA com tamanhos diferenciados, categorizadas em grande, médias e pequenas, segundo o conceito dos ribeirinhos; ii) UPA distribuídas ao longo do rio Juba, evitandose unidades muito próximas umas das outras; iii) UPA que exploram as agroflorestas como meio de sobrevivência familiar e; iv) UPA cujas famílias famílias têm residência fixa.

As UPA possuem as seguintes áreas: UPA1: 22 ha de área total e 20 ha de área manejada; UPA2: 8 ha de área total e 7 ha de área manejada; UPA3: 5 ha de área total e 4 ha de manejo; UPA4: 60 ha de área total e 10 de manejo; UPA5: 15 ha de área total e 14 de área manejada e a UPA6: 8 ha de área total e 7 ha de área de manejo, tendo-se em média 19,6 ha de área total e 10,3 ha de área manejada.

\section{Variáveis-indicadores utilizadas e avaliadas}

As variáveis-indicadores estão relacionadas com as condições edafo-climáticas e sua influência na produção agroflorestal; com a potencialidade agroflorestal para a produção de produtos madeireiros e não-madeireiros existentes nas UPA e com a geração de renda. 


\section{ACTA AMAZONICA}

AVALIAÇÃO DA SUSTENTABILIDADE AGROAMBIENTAL DE UNIDADES PRODUTIVAS AGROFLORESTAIS EM VÁRZEAS FLÚVIO-MARINHA DE CAMETÁ - PARÁ

\section{Variáveis-indicadores relativas às condições edafo-climáticas}

- Clima: referentes à pluviosidade, temperatura e balanço hídrico do município, no que diz respeito a suficiência ou limitação em termos de disponibilidade hídrica no solo;

- Solo: diz respeito à fertilidade revelada pela análise de solo e pelos estudos existentes sobre a aptidão agrícola dos solos do município, voltados para o sistema de produção agroflorestal originado de uma mata nativa.

\section{Variáveis-indicadores relativas à potencialidade agroflorestal das UPA}

- Estrutura fitossociológica da agrofloresta: relacionada à identificação das espécies, nível de abundância absoluta, densidade relativa e volume;

- Espécies ocorrentes e o potencial para geração de renda e/ou consumo nas UPA: relacionada à classificação das espécies quanto a potencialidade comercial, em níveis de comercialização;

- Potencial de produção florestal madeireiro e nãomadeireiro: relacionado à estimativa dos estoques madeireiro e não-madeireiro a serem extraídos da agrofloresta;

Para a obtenção da estimativa do potencial para extração de produtos madeireiros anual por hectare, foram estabelecidos determinados procedimentos com vistas a sustentabilidade do ecossistema agroflorestal e dos resultados econômicos, tais como:

- Exploração das espécies comerciais e potenciais para remoção;

- Volume total de madeira, considerando-se somente as espécies que apresentam densidade relativa e ou dominância relativa $\geqslant 1 \%$;

- Circunferência a altura do peito para corte (CAP) $\geqslant$ $94 \mathrm{~cm}$

- Volume de madeira destinado à comercialização e/ou uso na UPA, foi limitado a $10 \%$ do volume total obtido dos indivíduos com o CAP de corte, objetivando manter indivíduos adultos para produção de sementes destinadas à regeneração da espécie, venda de sementes para geração de rendas e garantir um estoque de árvores para extração planejada a cada ano;

- Como a geração de receitas tem origem nas espécies comerciais, seu consumo na UPA deve ser substituído pelas potenciais sempre que for possível;

- O consumo de madeiras nas UPA deve ser preferencialmente pelas espécies potenciais; $\mathrm{e}$

- Exploração anual de $10 \%$ a $25 \%$ da área manejada.

$\mathrm{O}$ volume foi obtido pela equação de regressão linear simples, utilizando-se o diâmetro à altura do peito com casca e a altura comercial estimada da árvore.

Para a obtenção da estimativa do potencial florestal para produção não-madeireiro por hectare ano, foram estabelecidos os seguintes procedimentos com vistas a sustentabilidade do ecossistema agroflorestal e obtenção de resultados socioeconômicos:

- Categorizar os produtos não-madeireiros em comerciais e potenciais, com o objetivo de identificar as espécies, que efetivamente, são geradoras de receitas, e/ou de consumo familiar;

- Estimar os rendimentos por espécies e/ou unidade de área, com base nas observações de campo, informações da extensão rural e índices teóricos.

\section{Renda bruta estimada do sistema de produção agroflorestal}

A renda da agrofloresta é gerada a partir do potencial florestal madeireiro e não-madeireiro, inclusive criação de aves e suínos, identificados na agrofloresta.

A renda bruta estimada do sistema agroflorestal, engloba o valor bruto da produção vendida e a produção consumida na unidade produtiva, obtida através da fórmula: $\mathrm{RBT}=\sum_{\mathrm{i}} \mathrm{P}_{\mathrm{i}} Q_{\mathrm{i}}$ em que:

$\mathrm{RBT}=$ renda bruta total, medida em $\mathrm{R} \$ / \mathrm{UP}$ e $\mathrm{R} \$ \mathrm{ha}$;

$\mathrm{P}_{\mathrm{i}}=$ preço do produto $\mathrm{i}$, medido em $\mathrm{R} \$$;

$Q \mathrm{i}=$ quantidade do produto $\mathrm{i}$.

A renda bruta estimada do sistema agroflorestal, está especificada por atividade, e os preços utilizados nos cálculos, são aqueles recebidos por cada família por unidade do produto comercializado ou consumido, no ano de referência 2000.

\section{Produção e renda atual das UPA}

Obtidos mediante a aplicação de entrevistas, cálculos de volumes produzidos e técnicas de orçamentos através das equações já mencionadas.

\section{Avaliação do potencial \\ de sustentabilidade agroambiental}

O nível de sustentabilidade agroambiental das UPA foi obtido a partir dos seguintes procedimentos:

1) Estabelecimento de 5 níveis de potencial de sustentabilidade em uma escala de valores cardinais de $1 \mathrm{a}$ 10 pontos para o enquadramento na dimensão estudada. Os níveis propostos são:

- Nível SP: plena potencialidade de sustentabilidade: $\mathrm{SP}=10$ pontos.

- Nível SA: alta potencialidade de sustentabilidade: 7,5 pontos $\leqslant$ SA $<10$ pontos

- Nível SM: mediana potencialidade de sustentabilidade: 5 pontos $\leqslant \mathrm{SM}<7,5$ pontos

- Nível SB: baixa potencialidade de sustentabilidade: 2,5 pontos $\leqslant \mathrm{SB}<5$ pontos

- Nível SS: sem potencialidade de sustentabilidade: 


\section{SS $<2,5$ pontos}

2) Estabelecidos os níveis de potencialidade de sustentabilidade agroambiental das UPA, adotou-se um procedimento semelhante para as variáveis-indicadores. Assim, foi admitido e atribuído o valor de 1 a 10 pontos possíveis, para o enquadramento das variáveis-indicadores segundo a realidade das UPA, a partir dos dados levantados e confrontados com índices teóricos, em uma das alternativas propostas (Anexo 1) formuladas com os seguintes critérios para pontuação:

Situação alternativas para o enquadramento das variáveis-indicadores:

- Situação/ condições existentes boas a muito boas $($ plena $)=10$ pontos

- Situação/ condições existentes regulares $=6$ pontos

- Situação/ condições existentes deficitárias e/ou ruins $=2$ pontos

Onde, boa a muito boa $=$ a situação não apresenta nenhum tipo de limitação para exploração agroflorestal e desenvolvimento das UPA ou quando a situação apresenta alguma limitação, esta não compromete a exploração agroflorestal e desenvolvimento das UPA; regular $=\mathrm{a}$ situação apresenta limitações que provocam ou limitam a exploração agroflorestal e o processo de desenvolvimento das UPA, porém não inviabiliza; ruim = a situação oferece remota possibilidade para a exploração agroflorestal e o processo de desenvolvimento das UPA.

O nível de potencial de sustentabilidade agroambiental das UPA foi obtido pelo valor da média aritmética das pontuações das variáveis-indicadores, enquadrada em um dos níveis propostos no item 1 .

\section{RESULTADOS}

\section{Clima}

A temperatura média anual é de $28^{\circ} \mathrm{C}$, a precipitação pluviométrica anual fica entre 2.000 a $2.250 \mathrm{~mm}$, podendo chegar no estuário a $2.600 \mathrm{~mm}$ anuais (Koch e Bartelt, 2000; IBGE, 2.001).

Há uma estação seca de pequena duração, que segundo Souza Neves (1981) vai de setembro a novembro, sem comprometer a disponibilidade de água no solo, uma vez que, o fluxo da maré a cada 12 horas eleva o lençol freático, que se aproxima da superfície do solo. Tal observação é válida para as várzeas, pois o balanço hídrico do município, no período de 1995 a 2000 (Figura 1) revela que a evapotranspiração potencial é maior que a precipitação pluviométrica, o que levaria a um déficit hídrico no solo, não fosse o movimento das marés.

Assim, as condições climáticas ocorrentes nas UPA, não apresentam nenhum tipo de limitação hídrica para o desenvolvimento de espécies vegetais que compõem os SAF das várzeas flúvio-marinhas.

\section{Solos}

As análises realizadas em material coletado nas UPA, e comparadas com solos das várzeas do rio Amazonas (Tabela 1) se revelaram menos férteis, devido as águas do rio Amazonas serem mais ricas em sedimentos, que são os responsáveis pelos teores altos dos nutrientes $\mathrm{K}, \mathrm{Ca}, \mathrm{Mg}$ e $\mathrm{P}$ revelados nas análises de solo (Falesi \& Silva, 1999), enquanto as várzeas das UPA Cametá são menos férteis em função do rio Tocantíns apresentar menos sedimentos, na área em que se deu a coleta do material, conforme observaram Uhl et al. (1997) e Koch \& Bartelt (2000) ao debitarem à hidréletrica de Tucuruí a redução dos teores de sedimentos e a conseqüente queda de fertilidade da várzea a jusante da barragem.

$\mathrm{O}$ baixo teor de $\mathrm{P}$ não compromete a exploração das agroflorestas nas várzeas, em razão das espécies nativas estarem adaptadas a tal situação, onde provavelmente a concentração do elemento não atingiu o valor mínimo (Lei de Mínimo), abaixo do qual as sínteses não podem mais fazer-se (Odun, 1983; Dajoz, 1983) ou ainda em razão de tais espécies apresentarem "Valência ecológica" elevada (Dajoz, 1983), deve ser levado em conta também, as estratégias de conservação de nutrientes, "eutrófica e oligotrófica" que ocorren nas florestas tropicais segundo Jordan \& Herrera (1981).

Com relação ao pH do solo igual a cinco, valor ácido, pelas mesmas razões explicitadas anteriormente, não chega a constituir um impedimento para o estabelecimento das espécies nativas que compóem os SAF ocorrentes no ambiente flúvio-marinho.

Em termos de aptidão agrícola, as terras estão classificadas como terras sem aptidão agrícola, segundo os estudos e procedimentos realizados por Oliveira Júnior et al (1998). Tal classificação é própria para preservação ambiental, o que remete a necessidade de mantê-las florestadas, sendo os SAF uma boa alternativa de uso dos solos.

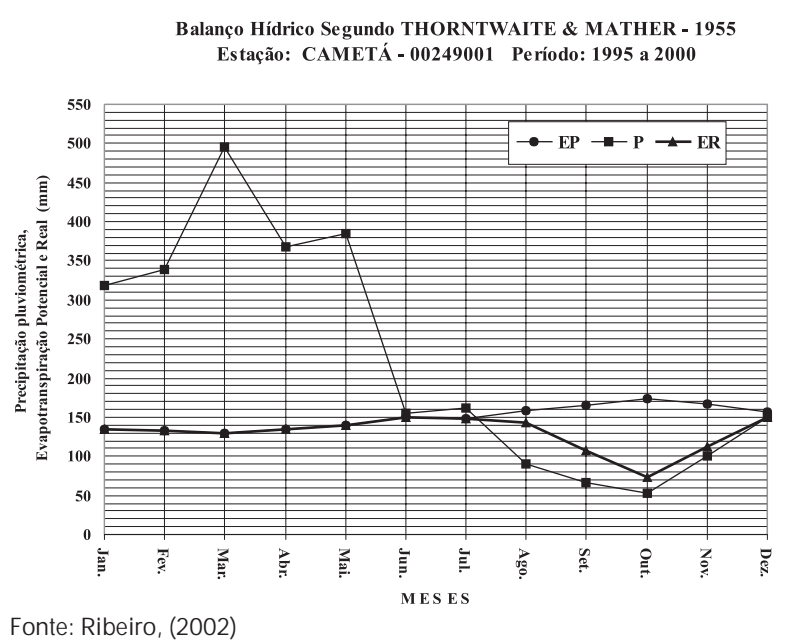

Figura 1 - Balanço hídrico do município de Cametá no período: 1995 a 2000 


\section{ACTA AMAZONICA}

Tabela 1 - Composição dos níveis de fertilidade entre solos das várzeas da ilha Ituqui (Santarém - PA), fazenda Santa Rita (Alenquer - PA), Cacual Grande (Monte Alegre - PA) e UPA (Cametá - PA) - 2001.

\begin{tabular}{lcccc}
\hline \hline \multicolumn{1}{c}{ Elementos e Valores } & Ituqui & Santa Rita & Cacual Grande & UPA \\
\hline $\mathrm{P}(\mathrm{mg} \mathrm{kg}-1)$ & $28(\mathrm{~A})^{*}$ & $7(\mathrm{~B})^{*}$ & $28(\mathrm{~A})$ & $3(\mathrm{~B})$ \\
$\mathrm{K}(\mathrm{mg} \mathrm{kg}-1)$ & $124(\mathrm{~A})$ & $85(\mathrm{~A})$ & $118(\mathrm{~A})$ & $67(\mathrm{M})$ \\
$\mathrm{Ca}\left(\mathrm{mmol}_{\mathrm{c}} \mathrm{dm}^{-3}\right)$ & $80(\mathrm{~A})$ & $92(\mathrm{~A})$ & $93(\mathrm{~A})$ & $66(\mathrm{~A})$ \\
$\mathrm{Mg}\left(\mathrm{mmol}_{c} \mathrm{dm}^{-3}\right)$ & $29(\mathrm{~A})$ & $40(\mathrm{~A})$ & $36(\mathrm{~A})$ & $27(\mathrm{~A})$ \\
$\mathrm{Al}\left(\mathrm{mmol}_{\left.\mathrm{c} \mathrm{dm}^{-3}\right)}\right.$ & $16(\mathrm{~A})$ & $24(\mathrm{~A})$ & $17(\mathrm{~A})$ & $10(\mathrm{M})$ \\
$\mathrm{PH}$ & 4,7 & 4,9 & 5,1 & 5,0 \\
$\mathrm{M} \mathrm{O}\left(\mathrm{g} \mathrm{dm}^{-3}\right)$ & $23(\mathrm{M})^{*}$ & $30(\mathrm{~A})$ & $29(\mathrm{~A})$ & (não determinado) \\
\hline \hline
\end{tabular}

Fontes: FALESI, et al. (1999), Ribeiro (2002)

O BS: * (A) - Valor alto; (M) - Valor médio; (B) - Valor baixo (Tomé Junior, 1997)

\section{Vegetação}

A estrutura fitossociológica da agrofloresta, está constituída por 26 famílias, 59 espécies e 730 indivíduos, considerando as plantas com CAP (circunferência a altura do peito) a partir de $10 \mathrm{~cm}$, identificadas em área amostral de 0,25 hectare.

Tabela 2 - Espécies mais representativas na estrutura fitossociológica horizontal dos SAF das UPA - Cametá-PA 2001-1 ha.

\begin{tabular}{|c|c|c|c|}
\hline $\begin{array}{l}\text { Nome } \\
\text { vulgar }\end{array}$ & $\begin{array}{c}\text { Nome } \\
\text { científico }\end{array}$ & Abundância & $\begin{array}{l}\text { Densidade } \\
\text { relativa \% }\end{array}$ \\
\hline \multicolumn{4}{|c|}{1 - Madeireiras } \\
\hline Virola & Virola surinamensis & 197,30 & 6,76 \\
\hline Andiroba & Carapa guianensis & 76,70 & 2,62 \\
\hline Mututí & $\begin{array}{c}\text { Pterocarpus } \\
\text { amazonicus }\end{array}$ & 28,00 & 0,96 \\
\hline Pracuúba & Mora paraensis & 6,70 & 0,23 \\
\hline Cajuí & $\begin{array}{l}\text { Anacardium } \\
\text { giganteum }\end{array}$ & 6,00 & 0,21 \\
\hline Pitaíca & $\begin{array}{c}\text { Swartzia } \\
\text { acuminata }\end{array}$ & 5,30 & 0,18 \\
\hline Mututirana & $\begin{array}{c}\text { Pterocarpus } \\
\text { officinalis }\end{array}$ & 3,30 & 0,11 \\
\hline Ceruzeiro & Allantoma lineata & 2,70 & 0,09 \\
\hline Cinzeiro & $\begin{array}{l}\text { Terminalia } \\
\text { amazonica }\end{array}$ & 2,70 & 0,09 \\
\hline \multicolumn{4}{|c|}{2 - Não-madeireiras } \\
\hline Açaí & Euterpe oleracea & $1.479,00$ & 50,63 \\
\hline Cacau & Theobroma cacao & 906,00 & 31,02 \\
\hline Buriti & Mauritia flexuosa & 10,00 & 0,34 \\
\hline Banana & Musa spp & 6,70 & 0,23 \\
\hline Ingá & Inga paraensis & 2,70 & 0.09 \\
\hline \multicolumn{2}{|c|}{3 - Outras espécies } & 187,60 & 7,304 \\
\hline \multicolumn{2}{|l|}{ Total } & $2.920,70$ & 100,00 \\
\hline
\end{tabular}

Fonte: Ribeiro, (2002)
A média por hectare é de $2.920,7$ indivíduos com CAP $\geqslant 10 \mathrm{~cm}$. Considerando a abundância absoluta, densidade relativa e o uso pelas famílias, as espécies de maior representatividade são: Euterpe oleracea (açaí) com 1479 exemplares $(50,63 \%$ da população total), Theobroma cacao (cacau) com 906 indivíduos (31,02 \% da população total), Virola surinamensis (virola) com 197 indivíduos (6,76 \% da população) e Pterocarpus amazonicus (mututi) com 28 exemplares (0,96 \% da população) (Tabela 2$)$.

Em termos de potencialidade da agrofloresta para geração de renda e/ou uso na unidade produtiva, as espécies florestais foram classificadas em três níveis de comercialização, de acordo com sua importância nos mercados local, circunvizinho e uso nas UPA: Nível 1 espécies não-comerciais, Nível 2 - espécies potenciais e Nível 3 - espécies comerciais (Anexo 2), assim especificados:

- Nível 1 - espécies não-comerciais: são aquelas que segundo os entrevistados, atualmente, não possuem nenhuma possibilidade de comercialização na comunidade e/ou vizinhança e raramente têm empregabilidade nas UPA, como alimento ou matéria-prima para construção de residências, embarcações, móveis ou lenha. Na média as espécies não-comerciais são em número de 14 , representam $23,7 \%$ da média total das espécies ocorrentes com um contingente de 44 indivíduos que somam $1,51 \%$ da população total (Tabela 3 e Figura 2).

- Nível 2 - espécies potenciais: estão relacionadas nesta categoria, aquelas que, segundo os ribeirinhos entrevistados, não são comercializadas na localidade $\mathrm{e}$ vizinhança, embora, tenham uso diversificado na unidade de produção, como produtoras de alimentos e matériaprima para construção de residências, embarcações, móveis, lenha e até uso medicinal. São espécies que pelas características ou qualidades desejáveis em determinados usos, permitem sua empregabilidade, lhes conferindo possibilidades de vir a serem comercializadas. 


\section{ACTA AMAZONICA}

AVALIAÇÃO DA SUSTENTABILIDADE AGROAMBIENTAL DE UNIDADES PRODUTIVAS AGROFLORESTAIS EM VÁRZEAS FLÚVIO-MARINHA DE CAMETÁ - PARÁ
Algumas dessas espécies, no passado recente, foram amplamente comerciais e relevântes na socioeconomia familiar ribeirinha, como é o caso do látex da Hevea brasiliensis (seringueira), atualmente apenas uma reserva comercial, em razão da baixa cotação do preço pago ao produtor, deixando de ser atrativa a sua exploração. Estão também enquadradas nessa categoria, espécies que geram produtos comerciais para outros mercados, como por exemplo, o fruto ou polpa do Mauritia flexuosa (buriti), comercializado na sede do município de Cametá e em outros mercados do Estado do Pará.

$\mathrm{Na}$ média, as potenciais, estão representadas por 29 espécies, somando 49,2\% do total de espécies, congregando 185 indivíduos, que perfazem $6,33 \%$ da população total (Tabela 3 e Figura 2).

- Nível 3 - espécies comerciais: estão elencadas nessa classe, aquelas que atualmente estão sendo comercializadas localmente, na vizinhança e sede do município de Cametá e municípios vizinhos.

São em número de 16 as espécies comerciais ocorrentes e representam $27,1 \%$ do número total de espécies, reunindo 2.692 indivíduos, correspondente a 92,16 \% da população existente (Tabela 3 e Figura 2).

Além dos níveis de comercialização, levantou-se através de observações de campo e pesquisa bibliográfica, alguns atributos das espécies que pudessem estar relacionados com a manutenção da fertilidade do solo (elevada produção e derrama de folhas) onde se destacam as espécies euterpe oleracea (açaí), Theobroma cacao (cacau), Theobroma grandiflorum (cupuaçu), Cecropia palmata (imbaúba), Hevea brasiliensis (seringueira) e Ficus antbelmintica (caxinguba), estas duas últimas citadas por Kolch \& Bartelt (2000) como espécies adubadeiras naturais; e/ou fornecimento de alimentos para a fauna silvestre, onde se destacam as espécies citadas, exceto a Ficus anthelmintica (caxinguba) e mais Psidium araca (araçá), Maximiliana régia (inajá), Inga paraensis (ingá), Astrocaryum murumuru (murumuru) e outras (Anexo 2).

\section{Potencial produtivo da agrofloresta}

A) Estimativa do potencial madeireiro

Verificou-se que somente a Virola surinamensis (virola) e Carapa guianensis (andiroba) apresentam potencial de produção madeireiro para extração comercial, conforme detalhamento apresentado e evidenciado nas Figuras 3 a 6. Tais resultados foram obtidos a partir das dez espécies que se apresentam na estrutura fitossociológica dos SAF com densidades e dominâncias relativas $\geqslant 1 \%$ classificadas como comerciais e potenciais. O objetivo é verificar quais espécies apresentam potencial para extração madeireira de forma sustentável. Para tal, foram estabelecidas nove classes de circunferência a altura do peito - (CAP) com os dados do inventário florestal por hectare, com intervalos de dez cm em cada classe, exceto a primeira e última classe. A primeira classe contém um intervalo de $14 \mathrm{~cm}$, com o limite menor igual a dez cm de CAP e o limite maior com $24 \mathrm{~cm}$ de CAP, esta classe mostra a capacidade de regeneração natural da espécie através do número de indivíduos existentes. A última classe, com intervalo $\geqslant 94,25 \mathrm{~cm}$ de CAP, mostra o potencial da espécie com CAP de corte, ou seja, o número de indivíduos em condições de serem extraídos. As demais classes intermediárias mostram a evolução dos indivíduos entre a primeira e última classe, representando a continuidade e a oferta de indivíduos no presente e futuro para serem extraídos da agrofloresta. A ausência de indivíduos na maioria das classes considerada neste trabalho, indica limitações e/ou impedimentos relacionados ao fornecimento, com regularidade, de indivíduos para serem extraídos, podendo ainda ser um indicativo de provável desaparecimento da espécie do SAF, especialmente se os indivíduos existentes tiverem alcançado a senilidade. Assim tem-se um potencial para extração madeireira sustentável com pequenas extrações anuais da ordem de 9,95 m3/ha/ano (Tabela 4). As demais espécies madeireiras, comerciais e ou potenciais, apresentam ausência de plantas em mais de duas classes diamétricas, sendo necessário preservar as existentes com potencial de produção de sementes para a regeneração das espécies.

Tabela 3 - Nível de comercialização das espécies ocorrentes - abundância absoluta (Aa) e relativa (Dr) nas UPA - Cametá-PA - 2001- 1ha

\begin{tabular}{|c|c|c|c|c|c|c|c|c|c|c|c|c|c|c|}
\hline \multirow{2}{*}{$\begin{array}{c}\text { Nível de } \\
\text { comercialização }\end{array}$} & \multicolumn{2}{|c|}{ UP1 } & \multicolumn{2}{|c|}{ UP2 } & \multicolumn{2}{|c|}{ UP3 } & \multicolumn{2}{|c|}{ UP4 } & \multicolumn{2}{|c|}{ UP5 } & \multicolumn{2}{|c|}{ UP6 } & \multicolumn{2}{|c|}{ Total* } \\
\hline & $\mathrm{A} \mathrm{a}$ & $\operatorname{Dr}(\%)$ & $\mathrm{A} \mathrm{a}$ & $\operatorname{Dr}(\%)$ & $\mathrm{A} \mathrm{a}$ & $\operatorname{Dr}(\%)$ & $\mathrm{A} \mathrm{a}$ & $\operatorname{Dr}(\%)$ & $\mathrm{A} \mathrm{a}$ & $\operatorname{Dr}(\%)$ & $\mathrm{Aa}$ & $\operatorname{Dr}(\%)$ & $\mathrm{A} \mathrm{a}$ & $\operatorname{Dr}(\%)$ \\
\hline $\begin{array}{l}\text { 1- Espécies } \\
\text { não-comerciais }\end{array}$ & 6 & 23,1 & 4 & 15,4 & 4 & 21,1 & 3 & 16,7 & 2 & 15,4 & 4 & 13,8 & 14 & 23,7 \\
\hline $\begin{array}{l}\text { 2- Espécies } \\
\text { potenciais }\end{array}$ & 12 & 46,1 & 10 & 38,5 & 7 & 36,8 & 9 & 50 & 6 & 46,1 & 15 & 51,7 & 29 & 49,2 \\
\hline $\begin{array}{l}\text { 3- Espécies } \\
\text { comerciais }\end{array}$ & 8 & 30,8 & 12 & 46,1 & 8 & 42,1 & 6 & 33,3 & 5 & 38,5 & 10 & 34,5 & 16 & 27,1 \\
\hline Total & 26 & 100 & 26 & 100 & 19 & 100 & 18 & 100 & 13 & 100 & 29 & 100 & 59 & 100 \\
\hline
\end{tabular}

Fonte: Ribeiro, (2002)

O BS:* Total sem repetição 


\section{ACTA AMAZONICA}

$\mathrm{Na}$ identificação das práticas de manejo adotadas, verificou-se que é elevado o número de espécies cujo CAP de corte se situa entre $30 \mathrm{~cm}$ e $94 \mathrm{~cm}$ (Anexo 2).

B) Estimativa do potencial florestal não-madeireiro

$\mathrm{O}$ potencial não-madeireiro das agroflorestas nas UPA pesquisadas, tem a seguinte configuração (Tabela 4):

- Euterpe oleracea (açaí-fruto): observou-se que plantas com $\mathrm{CAP} \geqslant 34 \mathrm{~cm}$, em condições de regular a boa luminosidade apresentavam processos de floração e frutificação, representavam nas UPA pesquisadas, entre $9 \%$ e $30 \%$ da população existente de Euterpe oleracea (açaí). Considerou-se esse contigente de $30 \%$ como indivíduos potencialmente produtivos e $75 \%$ deles com produtividade média de quatro cachos de $3,75 \mathrm{~kg}$, o que renderia por hectare/ano, a média de $15 \mathrm{~kg}$ de frutos por estipe adulto. Tal rendimento embora próximo, é inferior, a média citada por Shanley et al. (1998) de 16 a $32 \mathrm{~kg} /$ estipe/ano. Com esse rendimento, a média por hectare/ano, entre as unidades produtivas, é de $5.127,5 \mathrm{~kg}$;

- Euterpe oleracea (açaí-palmito): a extração está estimada em $10 \%$ da população potencialmente produtiva, o que dá uma média anual por hectare, entre as UPA, de 148 palmitos. Tal rendimento está baseado no palmito como um sub-produto, decorrente das operações de limpeza em que são eliminados os indivíduos defeituosos, pouco produtivos e/ou muito altos, mantendo uma média de quatro à cinco indivíduos por touceira.

- Carapa guianensis (andiroba-semente/óleo): individuos com CAP $\geqslant 94 \mathrm{~cm}$ e altura média estimada a partir de 20 metros, podem ser consideradas plantas adultas e portanto, potencialmente produtoras de sementes. Como nem todos os indivíduos adultos produzem sementes anualmente, considerou-se $50 \%$ da população adulta como produtora de sementes, e um rendimento médio de $50 \mathrm{~kg}$ de semente/árvore/ano. Esse rendimento, se iguala ao limite menor, citado por Shanley et al. (1998) que se referem a média de produção entre os limites de 50 a $200 \mathrm{~kg}$ de sementes/árvore/ano.

Com o rendimento médio estabelecido de $50 \mathrm{~kg} /$ árvore/ ano, resulta uma produção média/ha/ano de 566,7 kg de sementes ou 113,3 litros de óleo de Carapa guianensis (andiroba) por hectare ano;

- Musa spp (banana-fruto): rendimento estimado com base em observações de campo em 50 \% dos indivíduos existentes, ou seja, um cacho para cada dois indivíduos. Tal rendimento, resulta uma produção média por hectare ano de 3,35 cachos; ${ }^{5}$

- Theobroma cacao (cacau-semente): observou-se que indivíduos com CAP $\geqslant 15 \mathrm{~cm}$, apresentavam processos de floração e frutificação. Considerou-se então esses indivíduos produtivos; porém o rendimento utilizado, varia por UPA, em função do desenvolvimento vegetativo e aspecto fitossanitário do cultivo, com a média variando entre 200 e 300 gramas de sementes seca por planta produtiva. O rendimento médio das plantas nas ilhas de Cametá é de 250 g/árvore/ano (Ceplac, 2001 - comunicação oral). Com esse rendimento, a produção média por hectare ano, é de 166,2 kg de sementes secas;

- Theobroma grandiflorum (cupuaçu): com base nas observações de campo o rendimento foi estimado em cinco frutos por planta, muito abaixo do rendimento médio de 20 a 30 frutos/planta (Coral, 1990), o que resulta em uma produção média anual por hectare de $3,3^{5}$ frutos;

- Virola surinamensis (virola-semente): observou-se que individuos com CAP $\geqslant 94 \mathrm{~cm}$ e altura média estimada a partir de 20 metros, podem ser consideradas plantas adultas e portanto, potencialmente produtoras de sementes. Para o cálculo da produção, considerou-se $50 \%$ da população adulta como produtora de sementes, com um rendimento médio de $60 \mathrm{~kg}$ de semente/árvore/ano. Esse rendimento, se iguala ao limite médio menor, citado por Clay e Clement (1993) que se referem à média entre os limites de 60 a 90 $\mathrm{kg}$ de sementes/árvore/ano. Com o rendimento médio estabelecido de $60 \mathrm{~kg} /$ árvore/ano, resulta uma produção média de $580 \mathrm{~kg} / \mathrm{ha} /$ ano de sementes;

As espécies potenciais, cujas produções são destinadas ao consumo da família, tiveram os procedimentos para o cálculo da produção, baseados em obsevações de campo, consolidados por UPA. Os dados a seguir apresentados de produção, constam da Tabela 4:

- Psidium araca (araçá-fruto): rendimento estimado em dez kg por árvore produtiva, resultando uma produção média anual por hectare de $6,7^{5} \mathrm{~kg}$;

- Mauritia flexuosa (buriti-fruto): rendimento estimado em $100 \mathrm{~kg}$ por árvore produtiva, resultando uma produção média anual por hectare de 866,7 kg;

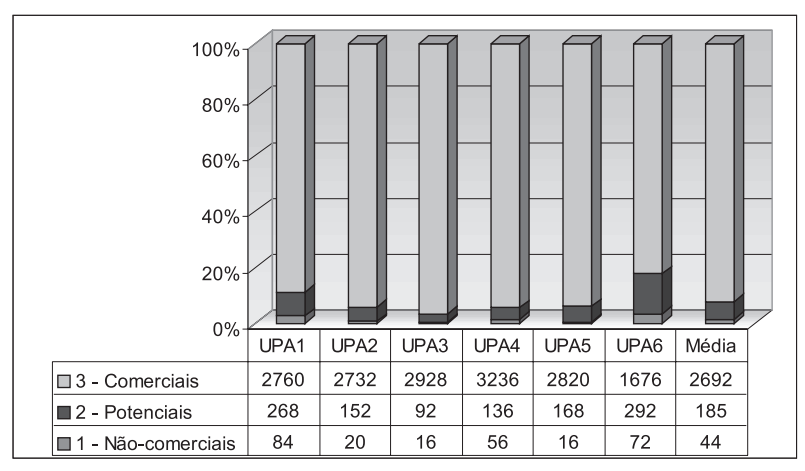

Figura 2 - Número total de plantas e porcentagem por nível de comercialização nas UPA - Cametá-PA - 2001- 1ha.

${ }^{5}$ São espécies existentes em um número reduzidos no SAF, cuja produçao e valor deve ser atribuido para se chegar ao valor total da produção do SAF mais realista possivel. Por outro lados, sua presença no SAF fas parte da concepção do agricultor e se destina a suprir uma demanda de consumo familiar. O utro aspecto relevante, é que tais culturas contribuem com a elevada bioiversidade do SAF, tornando-os agrossistemas próximos dos sistemas naturais que ocorrem na Amazônia, onde a densidade por ha é de 1 a 3 espécies, o que Ihes confere elevada fitossanidade e autodinâmica. 


\section{ACTA AMAZONICA}

AVALIACÃO DA SUSTENTABILIDADE AGROAMBIENTAL DE UNIDADES PRODUTIVAS AGROFLORESTAIS EM VÁRZEAS FLÚVIO-MARINHA DE CAMETÁ - PARÁ
( $\mathrm{N}^{\circ}$ de indivíduos)

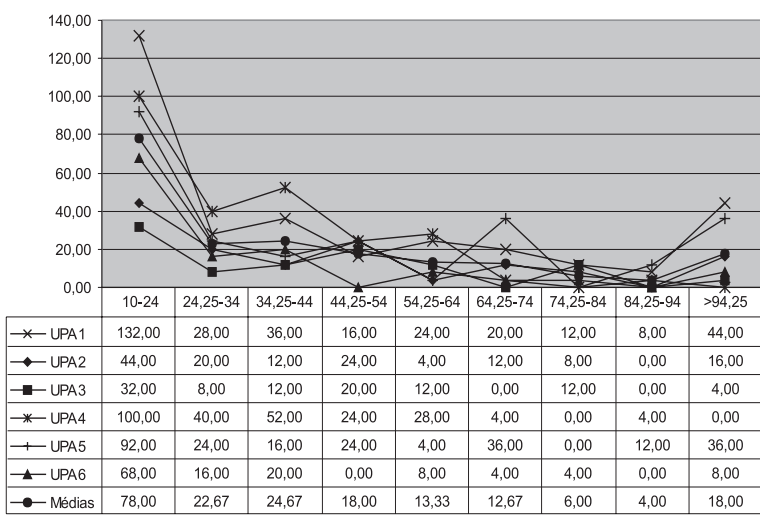

Figura 3 - Número de indivíduos de Virola surinamensis (virola) por classe de circunferência à altura do peito-CAP $(\mathrm{cm})$ nas UPA Cametá-PA - 2001.
( $\mathrm{N}^{\circ}$ de indivíduos)

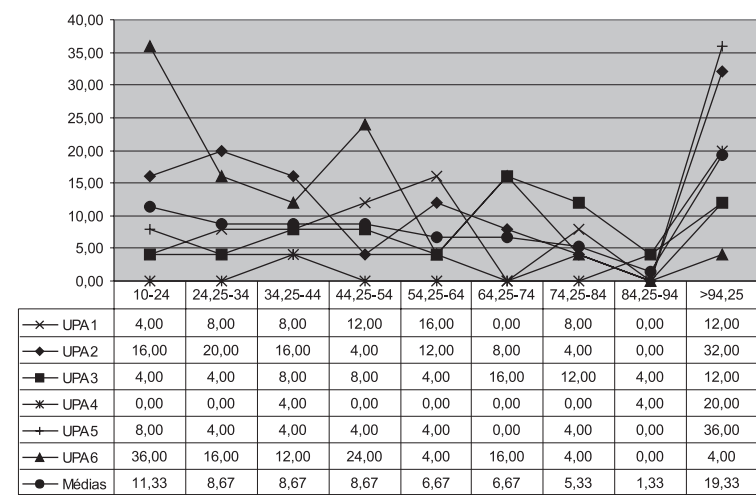

Figura 4 - Número de indivíduos de Carapa guianensis (andiroba) por classe de circunferência a altura do peito-CAP $(\mathrm{cm})$ nas UPA Cametá-PA - 2001.

A figura 3 mostra que os SAF apresentam indivíduos em todas as classes de circunferência à altura do peito - CAP. 0 maior número de indivíduos na classe de menor circunferência demonstra que a espécie Virola surinamensis (virola), apresenta uma boa capacidade de regeneração natural. As classes intermediárias, principalmente aquelas próximas a última classe (CAP $\geqslant 94,25 \mathrm{~cm}$ ), apresentam poucos indivíduos indicando irregularidade na oferta futura de indivíduos para corte. 0 baixo número de indivíduos nessas classes, pode ser resultante de retiradas de plantas com CAP <94,25 cm, o que está evidente nas UP 3, 4 e 6 . Com base na ocorrência em todas as classes, considerou-se esta espécie com potencial de extração de até 2 árvores/ha/ano, ou seja, 10\% da média com CAP $\geqslant 94,25 \mathrm{~cm}$.

A Figura 4 mostra que na média das classes os SAF apresentam indivíduos (andiroba) em todas as classes consideradas, indicando possibilidade de extração continuada. Com relação a classe inicial e as intermediárias, há uma certa regularidade com relação ao número de indivíduos, exceto a classe que antecede a última, que apresenta a média muito baixa em relação as demais e significa redução na oferta de árvores para corte no futuro próximo. A última classe apresenta a maior média entre as classes, inclusive maior que a primeira classe, onde se encontram os indivíduos de regeneração. A espécie, na média, possui potencial de extração de até duas árvores/há. A figura mostre que algumas UPA já não possuem condições de extração com regularidade, pois apresentam duas ou mais classes sem indivíduos.

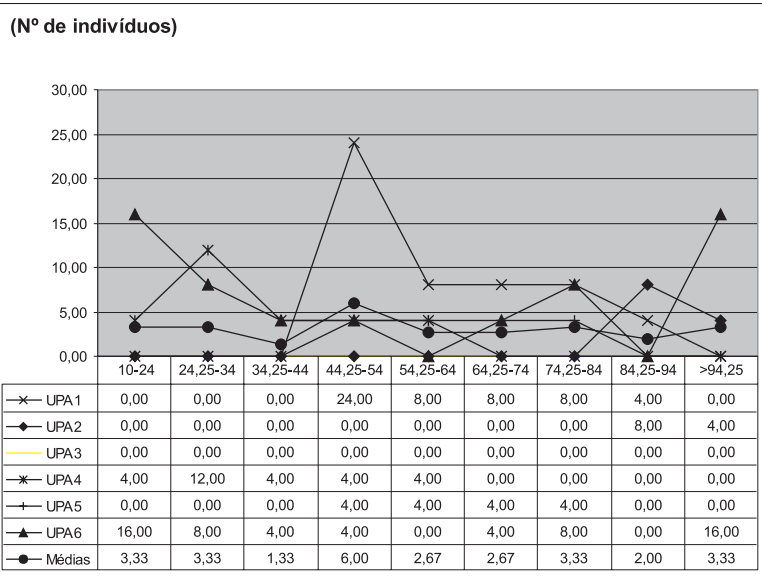

Figura 5 - Número de indivíduos de Pterocarpus amazonicus (mututi) por classe de circunferência a altura do peito-CAP $(\mathrm{cm})$ nas UPA - Cametá-PA-2001.

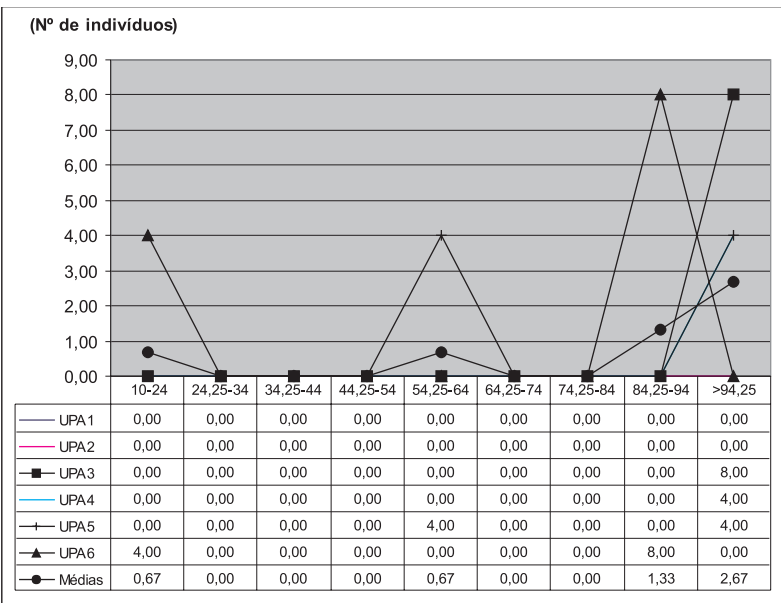

Figura 6 - Número de indivíduos de Mora paraensis (pracuúba) por classe de circunferência a altura-CAP $(\mathrm{cm})$ nas UPA-Cametá-PA-2001.

Há uma total irregularidade na distribuição do número de indivíduos pelas classes de circunferências e por SAF (Figura 5), o que resulta em médias baixas de indivíduos por classe, limitando a condição potencial de extração. Na primeira, segunda e terceira classes há poucos indivíduos, o que pode significar baixa capacidade regenerativa ou pode também, ser resultado de corte de indivíduos de forma indiscriminada em todas as classes de circunferência à altura do peito. Diante da distribuição pelas classes de uma média baixa, onde a maioria dosSAF apresentam mais de três classes sem indivíduos, considerou-se que essa espécie não apresenta potencial para extração madeireira.

A espécie Mora paraensis (pracuúba), não apresenta indivíduos na maioria das classes consideradas e quando apresenta é com baixa média, sendo que, a maioria dos indivíduos apresenta CAP >94,25 cm, prováveis indivíduos adultos, não apresentando nenhum indivíduo nas classes iniciais, portanto, sem regeneração. Logo, a espécie não apresenta potencial madeireiro para extração sustentável, sua existência nos SAF já se mostra comprometida. 


\section{ACTA AMAZONICA}

Tabela 4 - Estimativa do potencial florestal de produtos madeireiros, não-madeireiros e valor da produção das UPA Cametá-PA - 2001 - produção ha/ano.- valores médios de seis UPA

\begin{tabular}{|c|c|c|c|}
\hline Espécie & Unidade & Produção & Valor da produção \\
\hline 1 - Produto madeireiro & Potencial-m ${ }^{3}$ & Extração-m³ & $\mathrm{R} \$$ \\
\hline Carapa guianensis & 59,80 & 5,98 & 16,14 \\
\hline Virola surinamensis & 39,70 & 3,97 & 13,49 \\
\hline Sub-total & 99,50 & 9,95 & 29,63 \\
\hline \multicolumn{4}{|l|}{2 - Produtos não-madeireiros } \\
\hline \multicolumn{4}{|l|}{2.1 - Comercial } \\
\hline Euterpe oleracea (fruto) & $\mathrm{kg}$ & 5127,5 & $1.128,05$ \\
\hline Euterpe oleracea (palmito) & ud & 148,00 & 37,00 \\
\hline Carapa guianensis (semente) & $\mathrm{kg}$ & 566,70 & 56,67 \\
\hline Musa spp (fruto) & $\mathrm{ch}$ & 3,30 & 6,60 \\
\hline Theobroma cacao (semente) & $\mathrm{kg}$ & 166,20 & 159,55 \\
\hline Theobroma grandiflorum (fruto) & ud & 3,30 & 1,65 \\
\hline Virola surinamensis (semente) & $\mathrm{kg}$ & 580,00 & 69,60 \\
\hline Sub-total & & & $1.459,12$ \\
\hline \multicolumn{4}{|l|}{2.2 - Potencial } \\
\hline Psidium araca (fruto) & $\mathrm{kg}$ & 6,70 & 3,35 \\
\hline Mauritia flexuosa (fruto) & $\mathrm{kg}$ & 866,70 & 433,35 \\
\hline Anacardium giganteum (fruto) & $\mathrm{dz}$ & 22,40 & 22,40 \\
\hline Psidium guaiava (fruto) & $\mathrm{kg}$ & 6,70 & 3,35 \\
\hline Inga paraensis (fruto) & $\mathrm{dz}$ & 41,70 & 41,70 \\
\hline Citrus spp (fruto) & $\mathrm{kg}$ & 2,00 & 1,00 \\
\hline Mangifera indica (fruto) & $\mathrm{dz}$ & 8,30 & 8,30 \\
\hline Hevea brasiliensis (sernambi) & $\mathrm{kg}$ & 120,40 & 0,00 \\
\hline Spondias lutea (fruto) & l & 26,70 & 6,68 \\
\hline Sub-total & & & 520,13 \\
\hline Total & & & $2.008,88$ \\
\hline
\end{tabular}

O bs: kg=kilograma; ud=unidade; ch=cacho; dz=dúzia; I=litro

- Anacardium giganteum (cajui-fruto): rendimento estimado em 4,2 dúzias de frutos por árvore produtiva, resultando uma produção média anual por hectare de $22,4^{5}$ dúzias de frutos;

- Psidium guaiava (goiaba-fruto): rendimento estimado em dez kg por árvore produtiva, resultando uma produção média anual por hectare de $6,7^{5} \mathrm{~kg}$;

- Inga paraensis (ingá-fruto): rendimento estimado em 20,8 dúzias de frutos por árvore produtiva, resultando uma produção média anual por hectare de $41,7^{5}$ dúzias de frutos;

- Citrus spp (limão-fruto): rendimento estimado em $12 \mathrm{~kg}$ por árvore produtiva, resultando uma produção média anual por hectare de dois ${ }^{5} \mathrm{~kg}$;
- Mangifera indica (manga-fruto): rendimento estimado em 12,5 dúzias de frutos por árvore produtiva, resultando uma produção média anual por hectare de $8,3^{5}$ dúzias de frutos;

- Spondias lutea (taperebá-fruto): rendimento estimado em dez kg por árvore produtiva, resultando uma produção média anual por hectare de $26,7^{5} \mathrm{~kg}$.

Em termos do manejo dos SAF, verificou-se a existência de um calendário anual de atividades, cujas práticas estão distribuidas ao longo do ano, com ocupação da mão-de-obra em todos os meses do ano e maior demanda no período de julho a dezembro, quando ocorre a limpesa do SAF e colheita da Euterpe olerácea (açaî). Apurou-se ainda que as UPA possuem em média 2,78 equivalente homem/ano, ocupam 0,82 e sub-utilizam ou fica excedente 1,96 equivalente homem/ano, que deveria ser melhor utilizada (Ribeiro 2002). 


\section{ACTA AMAZONICA}

AVALIAÇÃO DA SUSTENTABILIDADE AGROAMBIENTAL DE UNIDADES PRODUTIVAS AGROFLORESTAIS EM VÁRZEAS FLÚVIO-MARINHA DE CAMETÁ - PARÁ

\section{Atual produção da agrofloresta}

As famílias retiram atualmente dos SAF (Tabela 5) cerca de $73,90 \mathrm{~m}^{3}$ de madeira em média por UPA, o que está acima da capacidade potencial de extração e, por outro lado, a produção não-madeireira se encontra em nível médio abaixo do potencial produtivo verificado, situação que denota provável deficiência no manejo agroflorestal adotado.

\section{Renda gerada decorrente do potencial agroflorestal}

A renda gerada decorrente do potencial agroflorestal, resulta da atribuição dos valores pagos aos ribeirinhos sobre a estimativa do potencial produtivo da agrofloresta.

A) Valor bruto da produção potencial florestal madeireira

Utilizando-se os valores pagos aos ribeirinhos, por $\mathrm{m}^{3}$ ( $\mathrm{R} \$ 2,70$ para a andiroba e $\mathrm{R} \$ 3,40$ para a virola) da madeira em tora nas UPA, e a produção potencial agroflorestal estimada, obteve-se um valor bruto da produção comercial, de R 29,63 (Tabela 4).

B) Valor bruto da produção potencial florestal nãomadeireiro

A partir dos valores brutos estimados para cada espécie produtora, o valor bruto da produção não-madeireira é da ordem de $\mathrm{R} \$ 1.979,25$, dos quais, $\mathrm{R} \$ 1.459,12$ são decorrentes dos produtos comerciais (Tabela 3). Tal valor bruto pode ser acrescido em $\mathrm{R} \$ 209,93$ para as UPA que extraem o óleo da semente de andiroba.
C) Valor bruto anual do potencial produtivo do sistema agroflorestal

$O$ valor bruto estimado por hectare ano, para o potencial produtivo do sistema agroflorestal, é da ordem de $R \$ 2.008,88$ dos quais, $R \$ 1.488,75$ são oriundos de atividades madeireiras e não-madeireiras comerciais, isto é, capazes de produzir ingressos financeiros nas unidades de produção (Tabela 4).

A Tabela 4, apresenta o valor bruto anual da produção agroflorestal potencial por hectare de $\mathrm{R} \$$ $2.008,88$ que aplicados sobre a área mínima identificada entre as UP pesquisadas, de quatro hectares, com manejo adequado, resultaria em uma renda bruta anual de $R \$ 8.035,52$, que representa cerca de 2,67 vezes a renda bruta média da agricultura familiar na Região Norte (INCRA, 2000).

A renda bruta potencial, gerada pela exploração de 4 hectares de agrofloresta, com manejo adequado, representa uma receita equivalente a 3,7 salários-mínimos de dezembro de 2000 (R\$ 180,00), o que evidencia a sustentabilidade econômica das UPA a partir da Agrofloresta.

\section{O potencial de sustentabilidade agroambiental das UPA}

Aplicada a metodologia de avaliação nas 12 variáveisindicadores, destacaram-se três variáveis-indicadores em condições boas a muito boas: condições climáticas por não apresentarem restrições/impedimentos ao desenvolvimento dos SAF com as atuais espécies nativas e aclimatadas; a vegetação relacionada às espécies

Tabela 5 - Produção média anual de madeiras, não-madeirais e criações, quantidades comercializada e consumida nas UPA - Cametá-PA, 2001.

\begin{tabular}{|c|c|c|c|c|c|}
\hline \multirow{2}{*}{ Produção do SAF por atividades } & \multirow{2}{*}{ Unidade de medida } & \multicolumn{2}{|c|}{ Quantidade } & \multicolumn{2}{|c|}{ Participação - \% } \\
\hline & & Venda & Consumo & Venda & Consumo \\
\hline \multicolumn{6}{|l|}{1 - Produção madeireira } \\
\hline Madeira em árvore & $M^{3}$ & 73,90 & 61,46 & 54,60 & 45,40 \\
\hline \multicolumn{6}{|l|}{2 - Produção não-madeireira } \\
\hline Açaí-fruto & lata-18l & 142,50 & 219,00 & 39,40 & 60,60 \\
\hline Açaí-palmito & unidade & 391,67 & - & 100,00 & - \\
\hline Andiroba-semente & kg & 250,00 & - & 100,00 & - \\
\hline Andiroba-óleo & 1 & 54,67 & 2,83 & 95,10 & 4,90 \\
\hline Buriti-fruto & lata-18l & - & 77,08 & - & 100,00 \\
\hline Cacau-semente & kg & 120,50 & 10,50 & 92,00 & 8,00 \\
\hline Banana & cacho & 8,33 & 13,50 & 38,20 & 61,80 \\
\hline \multicolumn{6}{|l|}{3 - Produção de aves e suínos } \\
\hline Aves & unidade & 4,00 & 16,00 & 20,00 & 80,00 \\
\hline Suínos & unidade & 0,30 & 5,50 & 5,20 & 94,80 \\
\hline
\end{tabular}

Fonte : Ribeiro, (2002) 


\section{ACTA AMAZONICA}

AVALIAÇÃO DA SUSTENTABILIDADE AGROAMBIENTAL DE UNIDADES PRODUTIVAS AGROFLORESTAIS EM VÁRZEAS FLÚVIO-MARINHA DE CAMETÁ - PARÁ comerciais que representam um percentual acima de 90 \% da população total existente; vegetação de espécies florestais não-madeireiras comerciais por representarem mais de $90 \%$ da população existente, indicativo do potencial produtivo da agrofloresta.

$\mathrm{Na}$ condição de variáveis-indicadores consideradas regulares, têm-se: a fertilidade dos solos, que dispensa o uso de adubações pela sua impraticabilidade no ecossistema flúvio-marinho, mas requer práticas de manejo solo x planta; a vegetação não-madeireira relacionada ao potencial estimado de produção ha/ano; a operação de manejo relacionada ao CAP de corte que pode prejudicar a produção de sementes e a regeneração das espécies; o calendário anual agroflorestal relacionado à época de realização de corte de espécies madeireiras que parece longo e a roçagem de limpeza e desbaste de touceiras de Euterpe oleracea (açaí) realizada em dois períodos, com baixa demanda de mão-de-obra, devendo haver melhor adequação do período.

Com relação às condições consideradas ruins, têm-se as variáveis-indicadores: a vegetação madeireira relacionada ao potencial de madeira para extração se situa abaixo dos índices teóricos potenciais de 3 a 6 árvores/ha/ano (Johns et al.,1998) ou $30 \mathrm{~m}^{3} / \mathrm{ha}$ (Scolforo, 1997); vegetação madeireira relacionada a atual extração ha/ano maior que o potencial estimado, empobrecendo e reduzindo o estoque atual de espécies madeireiras e; vegetação não-madeireira relacionada ao rendimento ha/ano, muito abaixo dos índices teóricos potenciais considerados para as várzeas. Por exemplo, o açaí sem manejo com potencial de $1.158 \mathrm{~kg} / \mathrm{ha}$ de frutos (Shanley et al., 1998) ou até $15 \mathrm{t} / \mathrm{ha}$ (Shanley et al., 1998; Nogueira et al., 1995 e Nogueira, 1999) em áreas manejadas, o que pode estar relacionado ao atual manejo adotado. Nesta condição tem-se ainda, a variável-indicador vegetação madeireira comercial em relação a população total, que representa menos de $10 \%$ da população total, o que é limitante para extração madeireira com ofertas anuais para corte.

O potencial de sustentabilidade agroambiental obteve uma média aritmética com valor igual a 5,6 pontos (Tabela 6), o que confere a ela "mediana potencialidade de sustentabilidade ( 5 pontos $\leqslant$ SM de $<7,5$ pontos). Significa que os SAF, no âmbito das variáveis-indicadores avaliados, apresentam condições de sustentabilidade nos aspectos climáticos, fertilidade do solo e produtos florestais nãomadeireiros. A exploração florestal madeireira não se apresenta em condições favoráveis, exigindo mudanças no manejo atual, ainda que possibilite uma extração anual reduzida. esta dimensão contempla os recursos naturais onde o sistema atual de exploração, implica na retirada (desgaste) do recurso diminuindo o estoque (no caso madeireiro), o que pode levar ao esgotamento do recurso, inviabilizando a permanência das famílias na área, caso não sejam adotadas práticas de manejo adequadas, visando a exploração sustentável dos SAF.

\section{CONCLUSÕES}

O sistema de produção agroflorestal apresenta mediana potencialidade de sustentabilidade agroambiental. Dentre os resultados econômicos para os agricultores, decorrentes dos SAF, destacam-se a elevada potencialidade produtiva para produtos não-madeireiros, com reflexo direto na segurança alimentar (a Euterpe olerácea e a Mauritia

Tabela 6 - Sustentabilidade agroambiental - pontuação das variáveis-indicadores e média aritmética - Cametá-PA - 2001.

Variáveis-indicadores

1. Condições climáticas

2. Condições de fertilidade do solo

3. Vegetação - espécies comerciais x população total

4. Vegetação - espécies madeireiras comerciais $x$ população total

5. Vegetação-espécies madeireiras potencial de extração ha/ano

6. Vegetação - espécies não-madeireiras comerciais x população total

7. Vegetação - espécies não-madeireiras potencial de produção ha/ano

8. Vegetação - espécies madeireiras, extração atual ha/ano

9. Vegetação - espécies não-madeireiras, produtividade ha/ano

10. Tecnologia de manejo - CAP de corte

11. Tecnologia de manejo - calendário agroflorestal anual

12. Tecnologia de manejo - práticas atuais

Pontuação total

Média aritmética
Pontuação

\begin{tabular}{c}
10,0 \\
6,0 \\
10,0 \\
2,0 \\
2,0 \\
10,0 \\
6,0 \\
2,0 \\
2,0 \\
6,0 \\
6,0 \\
\hline 6,0 \\
\hline 68,0 \\
\hline 5,6 \\
\hline
\end{tabular}

Fonte: Ribeiro, (2002) modificada. 


\section{ACTA \\ AMAZONICA}

AVALIAÇÃO DA SUSTENTABILIDADE AGROAMBIENTAL DE UNIDADES PRODUTIVAS

AGROFLORESTAIS EM VÁRZEAS FLÚVIO-MARINHA DE CAMETÁ - PARÁ flexuosa participam diariammente da dieta alimentar por ocasião da safra) e na geração de renda e as espécies madeireiras, como fornecedoras de matéria-primas necessárias para construções de moradias, abrigos, portos e embarcações. Todas, indispensáveis para a sobrevivência na várzea. As limitações dos SAF são a baixa potencialidade madeireira e o baixo rendimento das espécies nãomadeireiras, que refletem na geração de renda e por conseguinte no atendimento de necessidades que dependem de recursos financeiros para suas sastifações.

O potencial de sustentabilidade econômica, também fica comprometida pela mediana sustentabilidade agroflorestal que se movimenta em direção a baixa sustentabilidade pelo desgaste dos recursos madeireiros e baixo rendimento nãomadeireiro. Tal situação, exige uma ação mais determinada do poder público e das organizaçõse representativas dos agricultores, direcionadas aos fatores limitantes, objetivando eliminá-los e/ou neutralizá-los, o que propiciará oportunidades e possibilidades de elevação do nível de potencialidade de sustentabilidade verificado.

Para elevar o nível de sustentabilidade agroambiental das UPA, recomenda-se: i) capacitação da mão-de-obra rural em manejo florestal de uso múltiplo, gestão da UPA, comercialização e marketing de produtos agroflorestais; ii) para a manutenção e conservação da fertilidade dos solos, afetada pela hidrelétrica de Tucuruí, recomenda-se para composição dos SAF, espécies florestais nativas com elevada produção foliar e derrama de folhas, (ciclagem de nutrientes e maior disponibilidade de matéria orgânica) como a Hevea brasiliensis (seringueira), Ficus anthelmintica (caxinguba); espécies com valor ecológico e econômico, em razão da elevada derrama de folhas, produção de alimentos e geração de renda, como a Euterpe oleracea (açaî) e Theobroma cacau (cacau); espécies com valor econômico e de uso nas UPA, importantes para a geração de renda e matéria-prima como a Carapa guianensis (andiroba), Hura creptans (açacu), Minquartia guianensis (acariquara), Macrolobium sp (ipê-da-várzea), Licania mabuba (maúba), Calophyllum brasiliensis (jacareúba), Hieronima alchornoides (magonçalo), Virola surinamensis (virola); espécies importantes na alimentação familiar como a Mauritia flexuosa (buriti) e Spondias lútea (taperebá); espécies de importância ecológica na alimentação da fauna silvestre como a Inga paraensis (ingá) e Astrocarium murumuru (murumuru); espécies de importância como matéria-prima para lenha/ carvão como a Swartzia acuminata (pitaíca), Campsiandra laurifolia (acapurana), Penthacletbra macroloba (pracaxi), Pterocarpus amazonicus (mututi) e Pithecollobium latifolium (ingarana), as quais já vem sendo usadas na comunidade do Juba.

Recomenda-se a formulação de políticas de desenvolvimento diferenciadas por regiões fisiográficas, e no caso específico, instituir programas de desenvolvimento socioeconômico e ambiental para as áreas com ocorrência de várzeas flúvio-marinhas, destinados a promover de forma sustentável a exploração das agroflorestas; implantar agroindústrias comunitárias e apoiar à comercialização dos produtos agroflorestais nãomadeireiros, $100 \%$ naturais.

\section{BIBLIOGRAFIA CITADA}

Barros, A. C.; Uhl, C. 1996. Padrões, problemas e potencial da extração madeireira ao longo do rio Amazonas e do seu estuário. In: Barros, A. C.; Veríssimo, A. (Eds.). A expansão da atividade madeireira na Amazônia: impactos e perspectivas para o desenvolvimento do setor florestal no Pará. Imazon. Belém, Pará. p. 109 - 135.

Clay, J. W.; Clement, C. R. 1993. Selected species and strategies to enbance income generation from Amazonian forests. FAO, Roma. p. 58-195.

Coral, R. P. da S. 1990. O cupuaçu: boa opção para investimento. Belém, SAGRI. 38pp.

Dajoz, R. Ecologia geral. 1983. Vozes, Petrópolis. 472pp.

EMBRAPA, 1997. Manual de métodos de análise de solo. Serviço Nacional de Levantamento e Conservação de Solos. Documentos 1. Rio de Janeiro. 212 pp.

Falesi, I. C.; Silva, B. N. R. da. 1999. Ecossistema de várzea da região do baixo Amazonas. Embrapa Amazônia Oriental, Belém, Pará. 75pp.

Fenzl, N. 1997. Estudo de parâmetros capazes de dimensionar a sustentabilidade de um processo de desenvolvimento. In: XIMENES, T. (Org.). Perspectivas do desenvolvimento sustentável ( uma contribuição para Amazônia 21). UFPA/NAEA. Associação de Universidades Amazônicas. Belém, Pará. 657pp.

Guimarães, G. De A.; Bastos, J. B.; Lopes, E. de C. 1970. Método de análise física, química e instrumental de solos. IPEAN. Belém, Pará. 108pp.

IBGE. Cametá 1999 (folder). Cametá, Pará. Cametá 2001 (folder). Cametá, Pará.

INCRA, 2000. Novo retrato da agricultura familiar - o Brasil redescoberto. Brasília, DF. $74 \mathrm{pp}$.

Johns, J.; Barreto, P.; Uhl, C. 1998. Os danos da exploração de madeira com e sem planejamento na Amazônia oriental. Imazon. Belém, Pará. 40pp.

Jordan, C. F.; Herrera, R. 1981. Tropical rain forests: nutrients really critical ? The American Naturalist. 117: 167-180.

Koch, J. A.; Bartelt, D. 2000. Proposta para um manejo sustentável de floresta primária na base de distribuição de nutrientes dos solos e biomassa nas várzeas do baixo Tocantíns. FCAP/Projeto Várzea/Universidade Técnica de Dresden, (Relatório digitado). Belém, Pará. 27pp.

Nogueira, O. L.; Carvalho, C. J. R.; Muller, C. H.; Galvão, E. U. P.; Silva, H. M. e; Rodrigues, J. E. L. F.; Oliveira, M. do. S. P. de; Carvalho, J. E. U. de; Neto, O.G. da. R.; Nascimento, W. M. O. do; Calzavara, B.B. G. 1995. A cultura do açaí. Brasília. Embrapa-SPI. 50pp.

Nogueira, O. L. 1999. Estrutura e dinâmica populacional de açaizeiros nativos de várzeas na região do baixo Tocantíns, Estado do Pará. Boletim de pesquisa 15. Embrapa Amazônia Oriental. Belém, Pará. 21pp. 


\section{ACTA AMAZONICA}

Odum, E. P. 1983. Fundamentos de ecologia. Rio de Janeiro: Guanabara. 434pp.

Oliveira Júnior, R. C. De, ; Santos, P.L. Dos, ; Rodrigues, T. E. ; Valente, M.. A. 1998. Avaliação de aptidão agrícola das terras do Município de Cametá, Estado do Pará. EMBRAPA-CPATU, (Documentos, 130). Belém, Pará. 33pp.

Ribeiro, R. N. da, S. 2002. Avaliação do potencial de sustentabilidade de unidades produtivas agroflorestais em várzeas de influência flúvio-marinba, Cametá-Pará. Dissertação (Mestrado em Ciências Florestais) - FCAP, Belém, Pará. 194f.

Scolforo, J.R.S. 1997. Manejo florestal. Lavras: UFLA/FAEPE. 438pp.

Shanley, P.; Cymerys, M.; Galvão, J. 1998. Frutíferas da mata na vida amazônica. Belém: [s. n.], 127pp.

Souza Neves, A. D. de,. 1981. Levantamento e aptidão agrícola dos solos de Cametá. CEPLAC/DEPAE/COPES, 19p. (Comunicado Técnico, 19). Belém, Pará. 19pp.
Tomé Jr, J. B. 1997. Manual para interpretação de análise de solo. Agropecuária. Guaíba, Rio Grande do Sul. 247pp.

Uhl, C.; Bezerra, O.; Martini, A. 1997. Ameaça à biodiversidade na Amazônia Oriental. Imazon. (Série Amazônia, n. 6). Belém, Pará. 34pp.

Veríssimo, A.; Cavalcante, A.; Vidal, E.; Lima, E.; Pantoja, F.; Brito, M. 1999. O setor madeireiro no Amapá: situação atual e perspectivas para o desenvolvimento sustentável. Governo do Estado do Amapá: Imazon. Macapá, Amapá. 74pp.

\section{RECEBIDO EM 26/03/2003 \\ ACEITO EM 17/07/2004}

Anexo 1 - Sustentabilidade agroambiental - assertivas e pontuação das UPA estudadas, Cametá-PA, 2001.

Variáveis-indicadores e as assertivas propostas com a correspondente pontuação atribuída. Enquadramento da variável-indicador na pontuação segundo a realidade retratada do ecossistema de várzea flúvio-marinha, com base nos critérios de pontuação estabelecidos.

1. Clima:

- As condições climáticas não apresentam limitações para o desenvolvimento e produtividade das agroflorestas 10,0 pontos

- As condições climáticas apresentam algum tipo de limitação para o desenvolvimento e produtividade das agroflorestas 6,0 pontos

- As condições climáticas são limitantes 2,0 pontos

2. As condições de fertilidade do solo de várzea:

- São férteis suficientes, dispensando manejo do solo x planta 10,0 pontos

- Demandam insumos e/ou exigem práticas de manejo adequado de solo e planta 6,0 pontos

- Exigem elevadas dosagens de adubos químicos solúveis e/ou orgânicos 2,0 pontos

\section{Potencialidade produtiva do agroecossistema}

3. Vegetação - espécies comerciais x população total existente

- As espécies comerciais: $\mathrm{EC} \geqslant 80 \%$ da população total 10,0 pontos

- As espécies comerciais: $50 \% \leqslant \mathrm{EC}<80 \%$ da população 6,0 pontos

- As espécies comerciais: $\mathrm{EC} \leqslant 50 \%$ da população 2,0 pontos

4. Vegetação - espécies madeireiras comerciais existentes $\mathrm{x}$ população total

- As espécies madeireiras comerciais: $\mathrm{EM} \geqslant 50 \%$ da população 10,0 pontos

- As espécies madeireiras comerciais: $15 \% \leqslant \mathrm{EM}<50 \%$ da população 6,0 pontos

- As espécies madeireiras comerciais: $\mathrm{EM}<15 \%$ da população 2,0 pontos 


\section{ACTA AMAZONICA}

AVALIAÇÃO DA SUSTENTABILIDADE AGROAMBIENTAL DE UNIDADES PRODUTIVAS AGROFLORESTAIS EM VÁRZEAS FLÚVIO-MARINHA DE CAMETÁ - PARÁ

5. Vegetação - espécies madeireiras potencial de extração ha/ano

- Potencial extrativo acima dos índices teóricos 10,0 pontos

- Potencial extrativo igual ou próximo aos índices teóricos 6,0 pontos

- Potencial extrativo abaixo dos índices teóricos 2,0 pontos

6. Vegetação - espécies não-madeireiras comerciais x população total existente

- As espécies não-madeireiras representam: ENM $\geqslant 50 \%$ da população 10,0 pontos

- As espécies não-madeireiras representam: $15 \% \leqslant \mathrm{ENM}<50 \%$ da população 6,0 pontos

- As espécies não-madeireiras representam: ENM < 15\% da população 2,0 pontos

7. Vegetação - espécies não-madeireiras potencial de produção ha/ano

- Potencial produtivo acima dos índices teóricos 10,0 pontos

- Potencial produtivo igual/próximo dos índices teóricos 6,0 pontos

- Potencial produtivo abaixo dos índices teóricos 2,0 pontos

\section{Uso atual do ecossistema}

8. Vegetação - espécies madeireiras, extração atual ha/ano

- Atual extração abaixo do potencial produtivo 10,0 pontos

- Atual extração igual/próximo do potencial produtivo 6,0 pontos

- Atual extração acima do potencial produtivo estimado 2,0 pontos

9. Vegetação - espécies não-madeireiras, produtividade ha/ano

- Atual rendimento acima do potencial estimado 10,0 pontos

- Atual rendimento igual/próximo do potencial estimado 6,0 pontos

- Atual rendimento abaixo do potencial estimado 2,0 pontos

10. Tecnologia de manejo - diâmetro de corte das espécies madeireiras

- $\mathrm{O}$ diâmetro de corte favorece a regeneração natural por sementes 10,0 pontos

- O diâmetro de corte prejudica parcialmente a regeneração natural 6,0 pontos

- O diâmetro de corte prejudica a regeneração natural por sementes 2,0 pontos

11. Tecnologia de manejo - o calendário anual agroflorestal

- Contribui com a gestão das UP e está ajustado ao ambiente das várzeas 10,0 pontos

- Contribui com a gestão das UP, porém deve ser ajustado ao ambiente 6,0 pontos

- Não contribui com a gestão e deve ser modificado 2,0 pontos

12. Tecnologia de manejo - as atuais práticas agroflorestais e o rendimento do sistema

- As práticas estão adequadas aos SAF e devem ser mantidas 10,0 pontos

- As práticas não estão totalmente adequadas e devem ser ajustadas aos SAF 6,0 pontos

- As práticas devem ser totalmente modificadas para melhorar a funcionalidade e produtividade dos SAF 2,0 pontos 


\section{ACTA AMAZONICA}

Anexo 2 - Espécies vegetais, finalidade, uso e/ou atributo ambiental e nível de comercialização

\begin{tabular}{|c|c|c|c|}
\hline \multicolumn{2}{|c|}{ Espécie } & \multirow[t]{2}{*}{ Finalidade, uso e/ou atributo ecológico } & \multirow[t]{2}{*}{$\begin{array}{c}\text { Nível de } \\
\text { Comercialização }\end{array}$} \\
\hline Nome científico & Nome vulgar (1) & & \\
\hline Hura creptans & Açacú (314) & Madeira para serraria & 2 \\
\hline Erytrina glauca & Açacurana (188) & Madeira para habitação & 2 \\
\hline Euterpe oleracea & Açaí & $\begin{array}{l}\text { Alimentação humana e da fauna e boa } \\
\text { derrama foliar }\end{array}$ & 3 \\
\hline Campsiandra laurifolia & Acapurana (31) & Madeira para lenha ou carvão & 2 \\
\hline Minquartia guianensis & Acariquara (94) & Madeira para habitação & 3 \\
\hline Symphonia globulifera & Anani (94) & Madeira para habitaçãp & 3 \\
\hline Licania macrophyla & Anauerá (31) & Madeira para lenha ou carvão & 2 \\
\hline Carapa guianensis & Andiroba (94) & $\begin{array}{l}\text { Madeira para habitação, móveis, lenha, } \\
\text { medicina caseira }\end{array}$ & 3 \\
\hline Ficus nymphaeiflolia & Apuí & & 1 \\
\hline Psidium araca & Araçá & Alimentação humana e da fauna & 2 \\
\hline Macrolobium acaciaefolium & Araparí & Madeira para habitação & 2 \\
\hline Platonia insignis & Bacurí (94) & $\begin{array}{l}\text { Madeira para habitação, móveis e } \\
\text { alimentação humana }\end{array}$ & 2 \\
\hline Musa sp. & Bananeira & Alimentação humana e da fauna & 3 \\
\hline Mauritia flexuosa & Buriti & Alimentação humana, da fauna e artezanato & 2 \\
\hline Theobroma cacao & Cacau & $\begin{array}{l}\text { Alimentação humana, da fauna e boa } \\
\text { derrama foliar }\end{array}$ & 3 \\
\hline anacardium giganteum & Cajuí & Alimentação humana, da fauna e madeira & 2 \\
\hline Stetculia speciosa & Capoteiro (31) & Madeira para lenha e/ou carvão & 2 \\
\hline Ficus anthelmintica & Caxinguba & Madeira para habitação e boa derrama foliar & 2 \\
\hline Allantoma lineata & Ceruzeiro (94) & Madeira para habitação & 3 \\
\hline Terminalia amazonica & Cinzeiro (94) & Madeira para habitação, lenha ou carvão & 3 \\
\hline Theobroma grandiflorum & Cupuaçu & $\begin{array}{l}\text { Alimentação humana e boa derrama de } \\
\text { folhas }\end{array}$ & 3 \\
\hline Matisia paraensis & Cupuaçurana (63) & Madeira para habitação, lenha e/ou carvão & 2 \\
\hline Guatteria poeppigiana & Envira preta $(31)$ & Madeira para lenha e/ou carvão e fibra & 3 \\
\hline Pithecollobium latifolium & Esponjeira & & 1 \\
\hline Artocarpus altilis & Fruta-pão & & 1 \\
\hline Psidium araca & Goiabeira & Alimentação humana e da fauna & 2 \\
\hline Cecropia palmata & Imbaúba (94) & $\begin{array}{l}\text { Madeira para lenha e carvão, alimento da } \\
\text { fauna e boa derrama foliar }\end{array}$ & 1 \\
\hline Maximiliana regia & Inajá & Alimentação humana e da fauna & 1 \\
\hline Quararibea guianensis & Inajarana & & 1 \\
\hline Inga paraensis & Ingá & $\begin{array}{l}\text { Alimentação humana, da fauna, madeira e } \\
\text { fixadora simbiontica de } \mathrm{N}\end{array}$ & 2 \\
\hline Pithecollobium latifolium & Ingarana (31) & $\begin{array}{l}\text { Madeira para lenha ou carvão e fixadora } \\
\text { simbiontica de } \mathrm{N}\end{array}$ & 1 \\
\hline Macrolobium sp. & Ipê da várzea (94) & $\begin{array}{l}\text { Madeira para embarcação, habitação e } \\
\text { móveis }\end{array}$ & 2 \\
\hline Calophyllum brasiliensis & Jacareúba (94) & Madeira para habitação e móveis & 2 \\
\hline Sarcaulus sp. & Jaraí branco (63) & Madeira para habitação & 2 \\
\hline
\end{tabular}




\section{ACTA AMAZONICA}

AVALIAÇÃO DA SUSTENTABILIDADE AGROAMBIENTAL DE UNIDADES PRODUTIVAS AGROFLORESTAIS EM VÁRZEAS FLÚVIO-MARINHA DE CAMETÁ - PARÁ

continuação Anexo - 2

\begin{tabular}{|c|c|c|c|}
\hline \multicolumn{2}{|c|}{ Espécie } & \multirow[t]{2}{*}{ Finalidade, uso e/ou atributo ecológico } & \multirow[t]{2}{*}{$\begin{array}{c}\text { Nível de } \\
\text { Comercialização }\end{array}$} \\
\hline Nome científico & Nome vulgar (1) & & \\
\hline Sarcaulus brasiliensis & Jaraí vermelho (63) & Madeira para embarcação e habitação & 2 \\
\hline Holopyxidium jarana & Jarana (63) & Madeira para habitação & 3 \\
\hline Jenipa americana & Jenipapo & Alimentação humana & 1 \\
\hline Raphia taedigera & Jupatí & Instrumentos de pesca e artezanato & 2 \\
\hline Hymanaea oblongifolia & Jutaí (94) & Madeira para habitação, e móveis & 3 \\
\hline Citrus sp. & Limoeiro & Alimentação humana & 2 \\
\hline Ocotea laxiflora & Louro da Várzea (63) & Madeira para habitação & 2 \\
\hline Hieronima alchornoides & Mangonçalo (63) & Habitação, lenha e carvão & 3 \\
\hline Bombax spruceanum & Mamorana (126) & Madeira para habitação & 2 \\
\hline Mangifera indica & Mangueira & Alimentação humana e da fauna & 2 \\
\hline Licania mahuba & Maúba (63) & Embarcação, habitação e móveis & 3 \\
\hline Astrocaryum murumuru & Murumuru & Alimentos para fauna & 1 \\
\hline Sapium marmieri & Murupita & & 1 \\
\hline Pterocarpus amazonicus & Mututi (31) & Madeira para lenha ou carvão & 2 \\
\hline Pterocarpus officinalis & Mututirana (31) & Madeira para lenha ou carvão & 2 \\
\hline Caryocar microcarpum & Piquiarana (94) & Madeira para habitação & 2 \\
\hline Swartzia acuminata & Pitaíca (31) & Madeira para lenha ou carvão & 2 \\
\hline Pentaclethra macroloba & Pracaxi (31) & Madeira para lenha ou carvão & 2 \\
\hline Mora paraensis & Pracuuba (157) & Madeira para embarcação, habitação e lenha & 3 \\
\hline Hevea brasiliensis & Seringueira & $\begin{array}{l}\text { Alimentos para fauna, látex e boa derrama } \\
\text { foliar }\end{array}$ & 2 \\
\hline Spondias lutea & Taperebá & Alimentação humana, da fauna e madeira & 2 \\
\hline Mabea angustifolia & Taquarí & & 1 \\
\hline Enterolobium schomburgkii & Timborana & & 1 \\
\hline Sloanea grandiflora & Urucurana & & 1 \\
\hline Virola surinamensis & Virola (94) & $\begin{array}{l}\text { Madeira para habitação, sementes para } \\
\text { venda }\end{array}$ & 3 \\
\hline
\end{tabular}

Fonte: Dados da pesquisa de campo*, (2001); Koch \& Bartelt (2000)

O BS: (1) 0 número entre parêntese é o CAP de corte (aproximado) das espécies madeireiras. 